Research Article

\title{
Preparation of Zirconium Oxide Powder Using Zirconium Carboxylate Precursors
}

\author{
Mohammed H. Al-Hazmi, ${ }^{1}$ YongMan Choi, ${ }^{1}$ and Allen W. Apblett ${ }^{2}$ \\ ${ }^{1}$ SABIC Technology Center, Riyadh 11551, Saudi Arabia \\ ${ }^{2}$ Chemistry Department, Oklahoma State University, Stillwater, OK 74078, USA \\ Correspondence should be addressed to Mohammed H. Al-Hazmi; hazmimh@sabic.com and YongMan Choi; choiy@sabic.com
}

Received 14 September 2014; Accepted 3 December 2014; Published 31 December 2014

Academic Editor: Dennis Salahub

Copyright (c) 2014 Mohammed H. Al-Hazmi et al. This is an open access article distributed under the Creative Commons Attribution License, which permits unrestricted use, distribution, and reproduction in any medium, provided the original work is properly cited.

\begin{abstract}
Zirconia was prepared at low temperatures $\left(<450^{\circ} \mathrm{C}\right)$ using single several source precursors based on zirconium carboxylates where the R groups were systematically varied. The combination of density functional theory (DFT) calculations and extensive characterization of the precursors (i.e., X-ray diffraction, thermal gravimetric analysis, infrared spectroscopy, and scanning electron microscopy) indicated that the carboxylic acid complexes may link the zirconium metal with a cis bidentate configuration. Periodic DFT calculations were performed to examine the interaction between monoclinic $\mathrm{ZrO}_{2}$ and propanoic acid. Dissociative adsorption takes place through the cis bidentate structure with an adsorption energy of $-1.43 \mathrm{eV}$. Calculated vibrational frequencies using the optimized structure are in good agreement with experimental findings.
\end{abstract}

\section{Introduction}

While zirconia $\left(\mathrm{ZrO}_{2}\right)$ finds extensive use as a ceramic material it also has important applications in catalysts [1]. Due to its unique chemical properties (i.e., surface acidity and basicity $[2,3])$, it is a valuable catalyst for elimination, dehydration, hydrogenation, and oxidation. As reported previously [4, 5], the properties of tetragonal zirconia $\left(\mathrm{t}-\mathrm{ZrO}_{2}\right)$ that is employed in the aforementioned applications are highly dependent on the precursors used for its preparation. To date, most interest has focused on the preparation of a stable $\mathrm{ZrO}_{2}$ powder at $\angle 450^{\circ} \mathrm{C}$ by using different precursors [6] including zirconium carboxylates. The latter can be prepared straightforwardly by the reaction of sodium carboxylate with an aqueous solution of a zirconium salt [7], leading to the linking of zirconium cations to the carboxylate anions. One of the most widely used precursors for the synthesis of zirconia may be zirconium acetate-based ones [8-13]. For example, zirconium tetraacetate can be prepared by the reaction of zirconium tetrachloride with an excess of acetic acid at $80^{\circ} \mathrm{C}$ [8]. Refluxing the mixture to the boiling point produces the formation of zirconium oxyacetate $[8,9]$. Zirconium oxyacetate, $\mathrm{Zr}_{4} \mathrm{O}_{3}\left(\mathrm{CH}_{3} \mathrm{COO}\right)_{10} \cdot 3 \mathrm{H}_{2} \mathrm{O}$, can be also prepared by refluxing of a small amount of zirconium oxychloride with acetic acid [14]. Recently, Guo and Chen [15] reported a novel zirconium oxy-hydroxy acetate complex synthesized from zirconium oxychloride and acetic acid solution, followed by a precipitation with concentrated ammonium hydroxide at $\mathrm{pH}=6$. The product was determined to be $\mathrm{Zr}_{4} \mathrm{O}_{3}(\mathrm{OH})_{7}\left(\mathrm{CH}_{3} \mathrm{COO}\right)_{3} \cdot 5 \mathrm{H}_{2} \mathrm{O}$ and produced a tetragonal zirconium oxide phase with a crystallite size of $30 \mathrm{~nm}$ when pyrolyzed at $545^{\circ} \mathrm{C}$. Regardless of the numerous studies, few studies have been carried out to investigate the preparation of zirconia from zirconium carboxylates complexes with varying $\mathrm{R}$-groups and their influence on the properties of the oxides from them. Therefore we recently reported a benchmark study using zirconium benzilate as a single source precursor for the synthesis of zirconia [16]. To more systematically understand the synthesis approach, the zirconia synthesis was executed with various types of carboxylate complexes derived from aliphatic and $\alpha$-hydroxyl carboxylic acids. In addition, periodic density functional theory (DFT) simulations were applied to support the experimental observation from infrared spectroscopy (IR). 


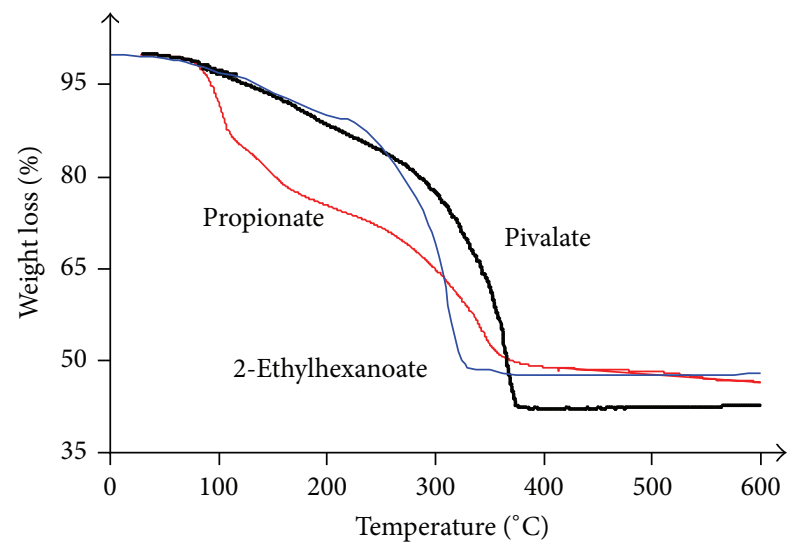

(a)

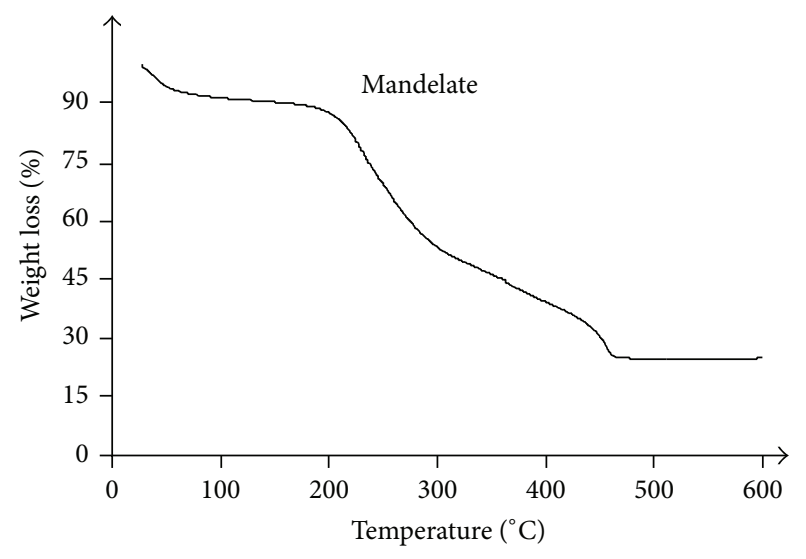

(b)

FiguRE 1: TGA curves for the prepared zirconium carboxylates of (a) Zr-1, Zr-5, and Zr-7 (propionate, pivalate, and 2-ethylhexanoate, resp.) and (b) Zr-10 (mandelate).

\section{Methods}

2.1. Experimental. Summarized in Table S1 (in Supplementary Materials available online at http://dx.doi.org/10.1155/ 2014/429751) are the chemical structures of the carboxylic acids used for the preparation of the zirconium carboxylates. Aqueous ammonium hydroxide $\left(\mathrm{NH}_{4} \mathrm{OH}\right.$, Scientific Products), zirconium oxychloride $\left(\mathrm{ZrOCl}_{2} \cdot 8 \mathrm{H}_{2} \mathrm{O}\right.$, Alfa Aesar), sodium bicarbonate $\left(\mathrm{NaHCO}_{3}\right.$, Alfa Aesar), 2-ethylhexanoic acid $\left(\mathrm{C}_{8} \mathrm{H}_{16} \mathrm{O}_{2}, \mathrm{MCB}\right), \alpha$-hydroxyisobutyric acid $\left(\mathrm{C}_{4} \mathrm{H}_{8} \mathrm{O}_{3}\right.$, Fluka), propanoic acid $\left(\mathrm{C}_{3} \mathrm{H}_{6} \mathrm{O}_{2}\right.$, Aldrich), sodium butyrate $\left(\mathrm{C}_{4} \mathrm{H}_{7} \mathrm{O}_{2} \mathrm{Na}\right.$, Aldrich), isobutyric acid $\left(\mathrm{C}_{4} \mathrm{H}_{8} \mathrm{O}_{2}\right.$, Aldrich), pivalic acid $\left(\mathrm{C}_{5} \mathrm{H}_{10} \mathrm{O}_{2}\right.$, Aldrich), mandelic acid $\left(\mathrm{C}_{8} \mathrm{H}_{8} \mathrm{O}_{3}\right.$, Aldrich), and hydroxypivalic acid $\left(\mathrm{C}_{5} \mathrm{H}_{10} \mathrm{O}_{3}\right.$, Aldrich) were used without further purification. Zirconium carboxylates precursors were prepared from the reaction of zirconium oxychloride with the sodium or ammonium carboxylic acid salts of the acids listed above. These syntheses are summarized in Table S2. The yields using zirconium carboxylate precursors were $\sim 90 \%$. The precipitates were washed several times with distilled water and subsequently dried in an oven at $120^{\circ} \mathrm{C}$ for 12 hours. They were then calcined at different temperatures in air. The chloride content was determined using a conventional gravimetric analysis [17] to confirm that no chloride ions were left in the solution.

The precursors and zirconia powders were characterized by the Brunauer-Emmett-Teller (BET) multilayer nitrogen adsorption method (Quantachrome Nova 1200), thermogravimetric analyses (Seiko EXSTAR 6000 TG/DTA 6200), scanning electron micrograph (SEM) (JEOL JXM 6400), diffuse reflectance infrared spectroscopy (Nicolet Magna-IR 750), and X-ray powder diffraction (XRD) patterns using copper $\mathrm{K}_{\alpha}$ radiation with a wavelength of $1.5418 \AA$ (Bruker AXS D8). The volume fraction of the tetragonal and monoclinic phases ( $\mathrm{t}-\mathrm{ZrO}_{2}$ and $\mathrm{m}-\mathrm{ZrO}_{2}$, resp.) and the relative ratio of $\mathrm{t}-\mathrm{ZrO}_{2}$ to $\mathrm{m}-\mathrm{ZrO}_{2}$ were determined using the method proposed by Toraya and coworkers [18] (see supporting information).
2.2. Computational. To examine the interaction between zirconia and carboxylic acid, periodic DFT calculations [19] were performed using Vienna ab initio simulation package (VASP) [20, 21]. The projector augmented wave method (PAW) [22] with the generalized gradient approximation (GGA) using the Perdew-Burke-Ernzerhof (PBE) functional [23] was used. In keeping with previous studies [16, 24], a stable $(\overline{1} 11)$ plane with a $(2 \times 2)$ surface was utilized. Similar to the previous study [24], a supercell with $16 \mathrm{Zr}$ and $32 \mathrm{O}$ atoms was constructed. A vacuum space of $15 \AA$ and a $415 \mathrm{eV}$ kinetic energy cut-off for a plane wave basis set was applied. The Monkhorst-Pack [25] meshes with $(3 \times 3 \times 3)$ and $(3 \times$ $3 \times 1) \mathbf{k}$-points were used for bulk and surface calculations, respectively. For $2 \mathrm{D}$ surface calculations, half of the atomic layers were fixed to the bulk structure, and the remaining layers and the adsorbate were fully relaxed. Adsorption energies $\left(\mathrm{E}_{\mathrm{ads}}\right)$ were defined as $\mathrm{E}_{\mathrm{ads}}=\mathrm{E}\left(\right.$ adsorbate $\left./ \mathrm{ZrO}_{2}\right)-\mathrm{E}\left(\mathrm{ZrO}_{2}\right)$ - E(adsorbate), where $\mathrm{E}\left(\right.$ adsorbate $\left./ \mathrm{ZrO}_{2}\right), \mathrm{E}\left(\mathrm{ZrO}_{2}\right)$, and $\mathrm{E}$ (adsorbate) are the calculated energies of a carboxylic acid on zirconia, a bare zirconia, and gas-phase carboxylic acid. The surface coverage was $25 \%$ [24]. To support the infrared spectroscopic measurements, frequencies were also calculated on the basis of the optimized structures. In this study, we applied the same k-point used for geometry optimization since our previous study showed the minor difference between prediction and experiment [16].

\section{Results and Discussion}

3.1. Zirconium Carboxylate Precursors for Zirconia. Representative TGA curves for propionate, pivalate, 2-ethylhexanoate, and mandelate are shown in Figure 1. These demonstrate that the weight loss is correlated with the nature of the carboxylate ligands of the precursors and clearly show that the weight loss starts at room temperature and is complete between 400 and $500^{\circ} \mathrm{C}$. Furthermore, the TGA results illustrate that the total weight loss of the zirconium $\alpha$-hydroxyl carboxylate 
TABLE 1: The elemental analysis results for the synthesized zirconium carboxylate complexes.

\begin{tabular}{|c|c|c|c|c|c|}
\hline \multirow{2}{*}{ Sample } & \multicolumn{2}{|c|}{ Elemental analysis (\%) } & \multirow{2}{*}{ Proposed formula $^{a}$} & \multirow{2}{*}{ Expt. MW (g/mol) ${ }^{\mathrm{b}}$} & \multirow{2}{*}{ Theor. MW $(\mathrm{g} / \mathrm{mol})^{\mathrm{c}}$} \\
\hline & $\mathrm{C}$ & $\mathrm{H}$ & & & \\
\hline ZrAc & 14.1 & 2.81 & {$\left[\mathrm{Zr}_{4} \mathrm{O}_{4}(\mathrm{OH})_{3}(\mathrm{OAc})_{5}\right] \cdot 4 \mathrm{H}_{2} \mathrm{O}$} & 211 & 212 \\
\hline Zr-1 & 17.2 & 4.10 & {$\left[\mathrm{Zr}_{4} \mathrm{O}_{2}(\mathrm{OH})_{5}(\mathrm{OAP})_{5} \mathrm{Cl}_{2}\right] \cdot 8 \mathrm{H}_{2} \mathrm{O}$} & 273 & 267 \\
\hline $\mathrm{Zr}-2$ & 18.6 & 3.95 & {$\left[\mathrm{Zr}_{4} \mathrm{O}_{4}(\mathrm{OH})_{3}(\mathrm{OAP})_{5}\right] \cdot 7 \mathrm{H}_{2} \mathrm{O}$} & 252 & 243 \\
\hline $\mathrm{Zr}-3$ & 28.3 & 4.68 & {$\left[\mathrm{Zr}_{4} \mathrm{O}_{4}(\mathrm{OH})_{2}(\mathrm{BUT})_{6}\right] \cdot 2 \mathrm{H}_{2} \mathrm{O}$} & 254 & 256 \\
\hline $\mathrm{Zr}-4$ & 23.3 & 5.33 & {$\left[\mathrm{Zr}_{4} \mathrm{O}_{4}(\mathrm{OH})_{2}(\mathrm{ISBUT})_{6}\right] \cdot 8 \mathrm{H}_{2} \mathrm{O}$} & 289 & 292 \\
\hline Zr-5 & 35.0 & 7.08 & {$\left[\mathrm{Zr}_{4} \mathrm{O}_{4.5}(\mathrm{PA})_{7}\right] \cdot 5 \mathrm{H}_{2} \mathrm{O}$} & 304 & 309 \\
\hline $\mathrm{Zr}-6$ & 27.6 & 4.93 & {$\left[\mathrm{Zr}_{4} \mathrm{O}_{5}(\mathrm{HPA})_{6}\right] \cdot 8 \mathrm{H}_{2} \mathrm{O}$} & 326 & 323 \\
\hline $\mathrm{Zr}-7$ & 18.5 & 4.55 & {$\left[\mathrm{Zr}_{4} \mathrm{O}_{6}(\mathrm{OH})_{2}(\mathrm{EHA})_{2}\right] \cdot 7 \mathrm{H}_{2} \mathrm{O}$} & 259 & 227 \\
\hline $\mathrm{Zr}-8$ & 36.5 & 5.27 & {$\left[\mathrm{Zr}_{4}(\mathrm{OH})_{4}(\mathrm{HIBA})_{12}\right] \cdot 6 \mathrm{H}_{2} \mathrm{O}$} & 443 & 445 \\
\hline Zr-9 & 23.9 & 6.45 & {$\left[\mathrm{Zr}_{4} \mathrm{O}(\mathrm{OH})_{4}(\mathrm{HIBA})_{10}\right] \cdot 28 \mathrm{H}_{2} \mathrm{O}$} & 504 & 496 \\
\hline Zr-10 & 47.0 & 4.46 & {$\left[\mathrm{Zr}_{4} \mathrm{O}(\mathrm{OH})_{5}(\mathrm{MA})_{9}\right] \cdot 4 \mathrm{H}_{2} \mathrm{O}$} & 532 & 506 \\
\hline
\end{tabular}

${ }^{a}$ OAc, OAP, BUT, ISBUT, PA, HPA, EHA, HIBA, and MA stand for acetate, propionate, butyrate, isobutyrate, pivalate, hydroxypivalate, 2-ethylhexanoate, hydroxyl isobutyrate, and mandelate, respectively. ${ }^{b}$ They were obtained from the TGA and thermal analysis, ${ }^{c}$ from proposed formula.

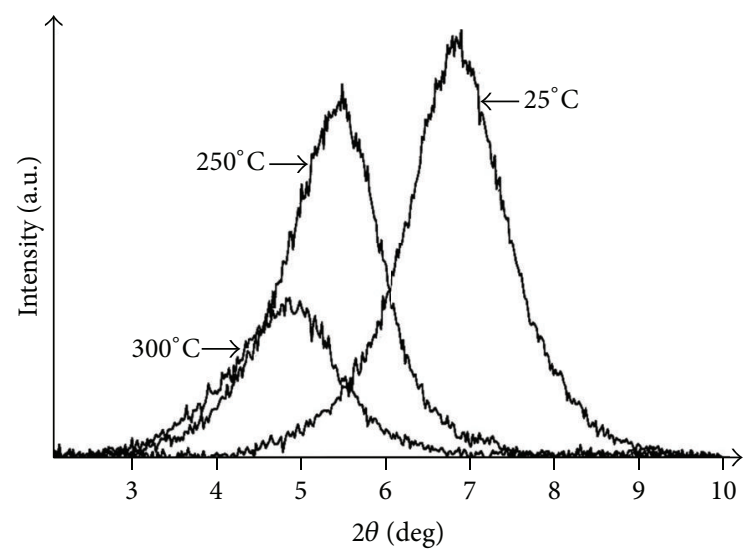

FIGURE 2: Low angle XRD patterns of the zirconium pivalate complex (Zr-5) calcined at different temperatures.

complexes (Figure 1(b)) is lower than that of the aliphatic zirconium carboxylates (Figure 1(a)). The reason may be the ability of the $\alpha$-hydroxyl carboxylates to chelate to a zirconium ion via the hydroxyl and the carboxylate. The formula weights of the complexes were calculated from the ceramic yields of $\mathrm{ZrO}_{2}$ from the TGA data. These were combined with the carbon and hydrogen content from elemental analysis to yield the proposed formulae for the zirconium carboxylates that are compiled in Table 1.

The low angle XRD patterns of the calcined zirconium pivalate complex at $25^{\circ} \mathrm{C}, 250^{\circ} \mathrm{C}$, and $300^{\circ} \mathrm{C}$ suggest the formation of a mesoporous solid (Figure 2). A single broad diffraction peak was observed with a d-spacing of $14.3 \AA$, $18.1 \AA$, and $20.0 \AA$ for the freshly synthesized complex and the products from its calcination at $250^{\circ} \mathrm{C}$ and $300^{\circ} \mathrm{C}$, respectively. The breadths of the reflection peaks reflect either a distribution of pore sizes or an organization of the pores in limited regions of the solid. The BET analysis of the zirconium pivalate complex shows a high surface area of $297 \mathrm{~m}^{2} / \mathrm{g}$, supporting an ordered porous structure. As shown in Figure 2, as the d-spacing increases, the scattering intensity decreases. This may indicate that the structure undergoes a contraction during the calcination and is transformed into a less ordered structure by the removal of the alkyl groups. This is also confirmed by the sharp decrease of the specific surface area during the calcination due to the collapse of the structure. The observed increase in the d-spacing might be due to the loss of adsorbed water molecules and a gradual thermal decomposition of the alkyl groups, leading to longer pores and an expansion in the distance between the structure layers. As reported previously $[17,18]$, the polymerization of the zirconium carboxylate tetramer may take place due to the presence of the $\mathrm{OH}$ groups forming a bridge between two tetramers. Such a polymerization process could be the reason for the formation of the high surface area porous zirconium carboxylates. As listed in Table 1, the synthesized zirconium $\alpha$ hydroxyisobutyrate (Zr-9) contains a large number of water molecules as compared to the other carboxylates. The extra water may be ascribed to water molecules that are linked to zirconium ion, resulting in a high polarization that induces strong interactions with other water molecules via hydrogen bonding.

Infrared spectroscopy was performed to examine the coordination modes of the carboxylate ligands. It is known that the carboxylate ligands bound in a bridging bidentate configuration have a $\Delta v$ value of about $160 \mathrm{~cm}^{-1}$ (splitting between the asymmetric and symmetric carbonyl stretching frequencies), while chelating bidentate carboxylates have a smaller $\Delta v$ value $\left(100 \mathrm{~cm}^{-1}\right.$ or less $)$. Monodentate carboxylates, on the other hand, result in a greater $\Delta v$ value of about $200 \mathrm{~cm}^{-1}[26,27]$. The infrared spectrum of the zirconium aliphatic carboxylate, zirconium propionate $(\mathbf{Z r}-\mathbf{1})$ (Figure 3(a)), shows a band centered at $3,377 \mathrm{~cm}^{-1}$ corresponding to the hydrogen bonded $\mathrm{O}-\mathrm{H}$ stretching band, while that at $3,643 \mathrm{~cm}^{-1}$ is related to the stretching mode for free $\mathrm{OH}$. The bands at 2,980 $\mathrm{cm}^{-1}$ and $2,930 \mathrm{~cm}^{-1}$ can be assigned to the asymmetric and symmetric methyl groups of the carboxylate ligands, respectively, while that at $1,340 \mathrm{~cm}^{-1}$ 


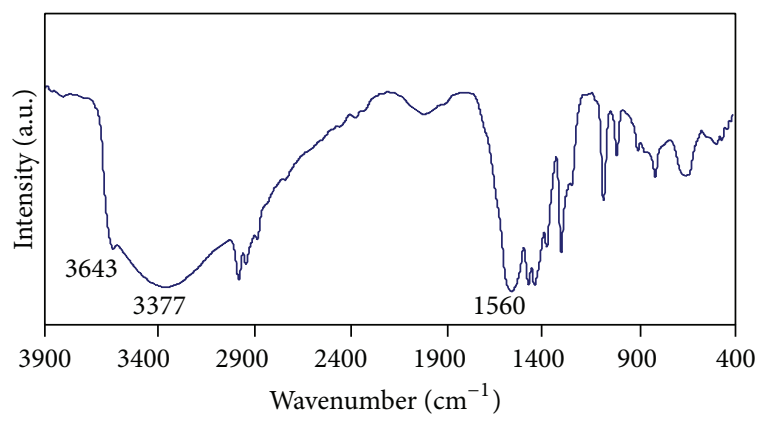

(a)

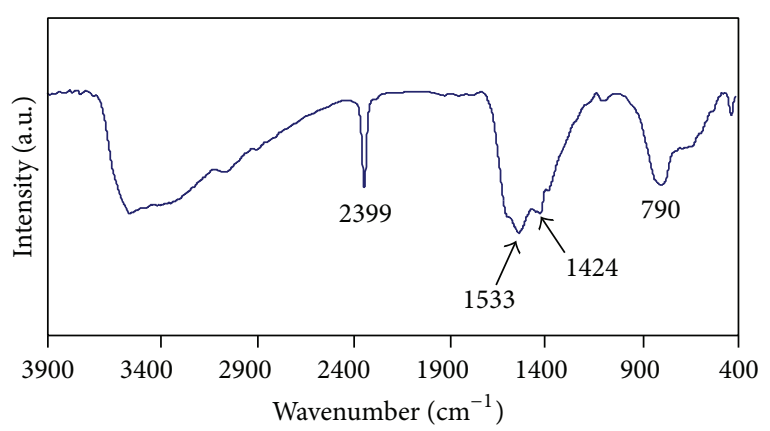

(b)

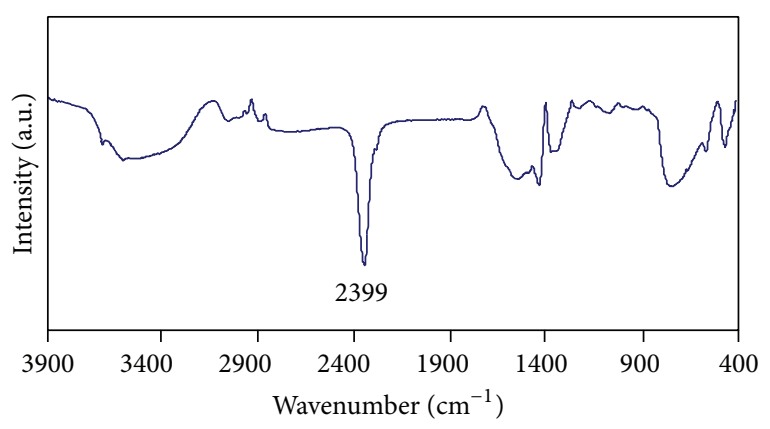

(c)

FIGURE 3: FTIR spectra of (a) the zirconium propionate complex $(\mathbf{Z r}-\mathbf{1})$ and its pyrolysis products treated at different temperatures at (b) $470^{\circ} \mathrm{C}$ and (c) $720^{\circ} \mathrm{C}$.

is attributed to the vibration mode of the $\mathrm{CH}_{3}$ group. The bands around $1,560 \mathrm{~cm}^{-1}$ and $1,439 \mathrm{~cm}^{-1}$ correspond to the asymmetric and symmetric carboxylate stretching vibrations, respectively. The IR band at about $1,470 \mathrm{~cm}^{-1}$ is attributed to the bending modes for $\mathrm{CH}_{3}$ and $\mathrm{C}-\mathrm{O}-\mathrm{H}$. Table 2 lists the stretching frequencies of the carboxylate carbonyl group $v_{\mathrm{COO}(\text { symm })}$ and $v_{\mathrm{COO}(\text { asymm) }}$ and the splitting $(\Delta \nu)$ between the asymmetric and symmetric carbonyl stretching frequencies of the zirconium carboxylate complexes. The $\Delta \nu$ values of $\alpha$ hydroxy carboxylate zirconium complexes were in the range $227-274 \mathrm{~cm}^{-1}$, while the other zirconium carboxylate complexes showed lower $\Delta \nu$ values in the range $121-152 \mathrm{~cm}^{-1}$. The lower $\Delta v$ values for nonhydroxylated zirconium carboxylates may be attributed to a bridging bidentate bonding mode for the carboxylates. The results in Table 2 also show that the $\Delta v$ values for the zirconium carboxylates increase slightly with
TABLE 2: Stretching frequencies of the carbonyl group ${ }^{a}$ for zirconium carboxylate complexes.

\begin{tabular}{lccc}
\hline Sample & \multicolumn{2}{c}{$\nu_{\mathrm{COO}}\left(\mathrm{cm}^{-1}\right)$} & $\Delta v\left(\mathrm{~cm}^{-1}\right)$ \\
\hline Zr-1 & Asym. & Sym. & 125 \\
Zr-2 & 1564 & 1439 & 121 \\
Zr-3 & 1560 & 1439 & 134 \\
Zr-4 & 1600 & 1466 & 141 \\
Zr-5 & 1585 & 1444 & 152 \\
Zr-6 & 1580 & 1428 & 125 \\
Zr-7 & 1556 & 1431 & 145 \\
Zr-8 & 1570 & 1425 & 227 \\
Zr-9 & 1615 & 1388 & 170 \\
Zr-10 & 1551 & 1381 & 274 \\
\hline
\end{tabular}

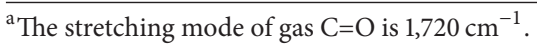

increasing chain length or branching of the carboxylate ligands. Among the aliphatic carboxylates, the propionate (Zr-2) has the lowest $\Delta v$ value of $121 \mathrm{~cm}^{-1}$, while pivalate (Zr-5) has the highest value of $152 \mathrm{~cm}^{-1}$. Furthermore, the aliphatic complexes (i.e., zirconium propionate, zirconium pivalate, zirconium hydroxypivalate, and 2-ethylhexanoate) show lower asymmetric stretching frequencies of the carbonyl groups than the $\alpha$-hydroxyl carboxylate zirconium complexes. A large shift of the carbonyl stretching frequencies between the free acid carbonyl $\left(1,700-1,730 \mathrm{~cm}^{-1}\right)$ and the complexes $\left(1,560-1,580 \mathrm{~cm}^{-1}\right)$ was observed. This shift is due to the fact that when the zirconium metal coordinates to the oxygen moiety of the carbonyl group in the carboxylate ligands with a bidentate configuration, the $\mathrm{C}-\mathrm{O}$ bonds are weakened due to the sharing of the carbonyl oxygen electrons in the bonding to the zirconium ions. In contrast, the $\alpha$ hydroxyl carboxylate complexes showed a higher asymmetric stretching for the carbonyl groups $\left(1,620-1,650 \mathrm{~cm}^{-1}\right)$. This may be due to the chelation of one oxygen atom of the carbonyl group and the oxygen of the $\alpha$-hydroxyl group to the zirconium ion to a five-membered ring. This will result in a monodentate carboxylate that is expected to have a large $\Delta \nu$ value.

3.2. Zirconia Prepared from Zirconia Carboxylate Complexes. Figures 3(b) and 3(c) show the infrared spectra of the products obtained from the pyrolysis of the zirconium propionate complex at different calcination temperatures. These display a sharp band at about $2,339 \mathrm{~cm}^{-1}$ that is attributed to the adsorbed $\mathrm{CO}_{2}$ species on the surface that resulted from the thermal decomposition of the carboxylate ligand. This assignment is in good agreement with previous studies on the adsorption of $\mathrm{CO}_{2}$ onto $\mathrm{ZrO}_{2}$ and modified $\mathrm{ZrO}_{2}$ [28, 29]. The peak observed at about $1,424 \mathrm{~cm}^{-1}$ for the zirconium propionate calcined at $470^{\circ} \mathrm{C}$ (Figure 3(b)) probably corresponds to the presence of some carbonate species adsorbed on the surface of $\mathrm{t}-\mathrm{ZrO}_{2}$. The calcined sample at $470^{\circ} \mathrm{C}$ shows a band at $1,533 \mathrm{~cm}^{-1}$ attributed to bidentate carbonate species present on the oxide surface. It is noted that according to the TGA 


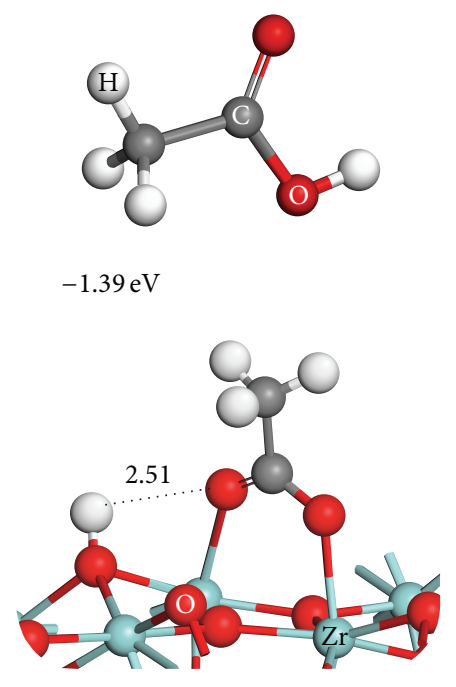

(a)
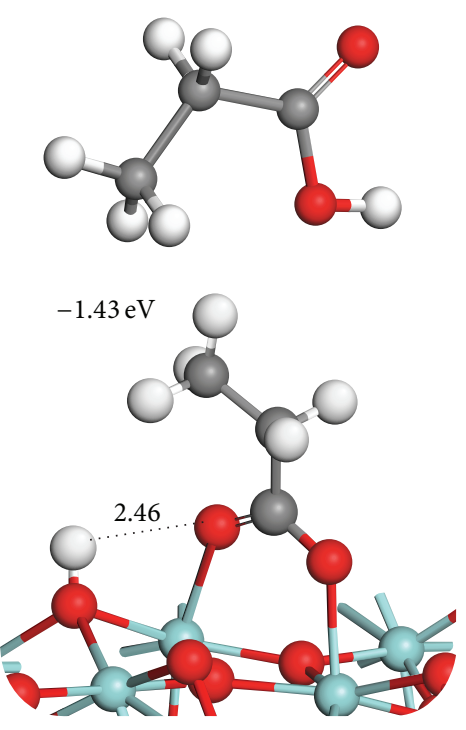

(b)

FIGURE 4: Geometrical illustration of acetic and propanoic acids and dissociatively adsorbed acetic and propionic acids on $\mathrm{m}-\mathrm{ZrO}_{2}$. The bond length between oxygen and hydrogen is in the unit of $\AA$. The energies are adsorption energies. The separated distance of surface carboxylate species is (a) $\sim 5.4 \AA$ and (b) $\sim 3.8 \AA$.

analysis, about $40 \%$ of its weight was lost when calcined at $\sim 470^{\circ} \mathrm{C}$, corresponding to the expected loss for $\mathrm{ZrO}_{2}$ formation. However, the sample color was still brown at this calcination temperature, indicating that the band at $1,533 \mathrm{~cm}^{-1}$ may be due to the bidentate carbonate and carbon species deposited on the oxide surface not the $\mathrm{ZrO}_{2}$ formation [28, 30]. The intensity of this peak decreased at the calcination temperature of $720^{\circ} \mathrm{C}$ (Figure 3(c)). The band observed at $\sim 790 \mathrm{~cm}^{-1}$ for the sample calcined at $470^{\circ} \mathrm{C}$ is probably due to the carbonate-water interaction. With increase in the calcination temperature, the intensity of this band decreased.

As described above, periodic DFT calculations were carried out to understand the interaction between stable $\mathrm{m}$ $\mathrm{ZrO}_{2}$ and acetic acid and propanoic acid. We chose the two acids since acetic acid is the smallest carboxyl acid, while propanoic acid is the smallest one used in the experiment. For the zirconia surface, a stable $(2 \times 2)(\overline{1} 11)$ plane was used as a surface. In this study, the cis configuration was examined, in accordance with a previous study [24], since the cis configuration is more stable than the trans configuration. Figure 4 schematically depicts the gas-phase acetic and propanoic acids. In addition, it was found that both acetic and propanoic acids are dissociatively adsorbed on the surface and their adsorption energies are $-1.39 \mathrm{eV}$ and $-1.43 \mathrm{eV}$, respectively. Both of the cis structures have similar $\mathrm{Zr}-\mathrm{O}$ distances $(\sim 2.2 \AA)$, while those of the $\mathrm{H}$ from the $\mathrm{OH}$ group are $2.51 \AA$ and $2.46 \AA$, indicating total dissociation. Based on the structure of propanoic acid (Figure 4(b)), a vibrationalfrequency calculation was executed to compare with the experimental results (Figure 3(a) and Table 2). Its surface $\mathrm{OH}$ stretching mode is calculated to be $3,605 \mathrm{~cm}^{-1}$, which is close to the typical OH stretching of $\mathbf{Z r - 1}$ (Figure 3(a); 3,643 $\mathrm{cm}^{-1}$ ). In particular, the calculated asymmetric mode for $\mathrm{COO}$

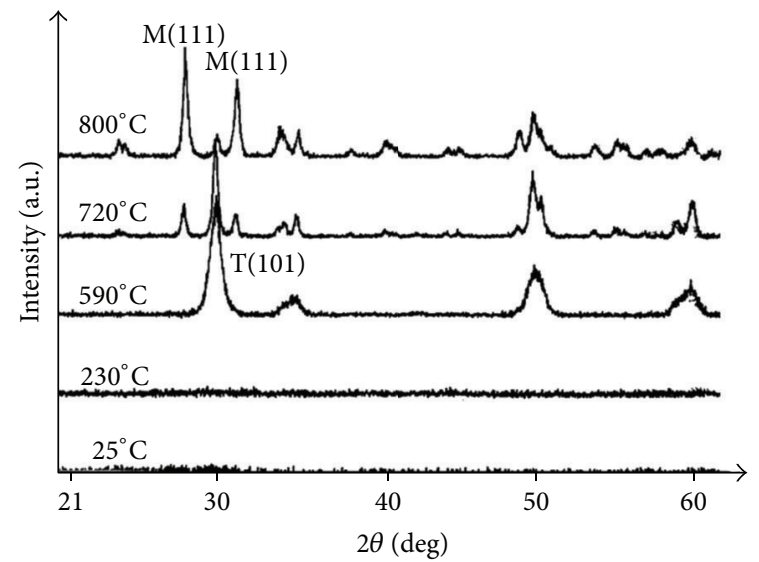

FIGURE 5: XRD patterns of the zirconium propionate complex (Zr1) calcined at different temperatures. " $T$ " and " $M$ " correspond to tetragonal and monoclinic phases, respectively.

is $1,497 \mathrm{~cm}^{-1}$, which is also in line with the experimental finding of $1,564 \mathrm{~cm}^{-1}$ (Table 2). The vibrational-frequency simulations along with geometry optimization support the conclusion that the cis bidentate structure is preferred to the trans configuration. As a matter of fact, it is highly difficult to construct a more plausible model to simulate the zirconium carboxylates as proposed (Table 1; $\left.\left[\mathrm{Zr}_{4} \mathrm{O}_{2}(\mathrm{OH})_{5}(\mathrm{OAP})_{5} \mathrm{Cl}_{2}\right] \cdot 8 \mathrm{H}_{2} \mathrm{O}\right)$. However, if one takes into account the hydrogen bond, more accurate results could be produced.

$\mathrm{X}$-ray powder diffraction demonstrated that the pyrolysis product from zirconium propionate at $230^{\circ} \mathrm{C}$ is amorphous (Figure 5). With further heating to $420^{\circ} \mathrm{C}$, a mixture of 


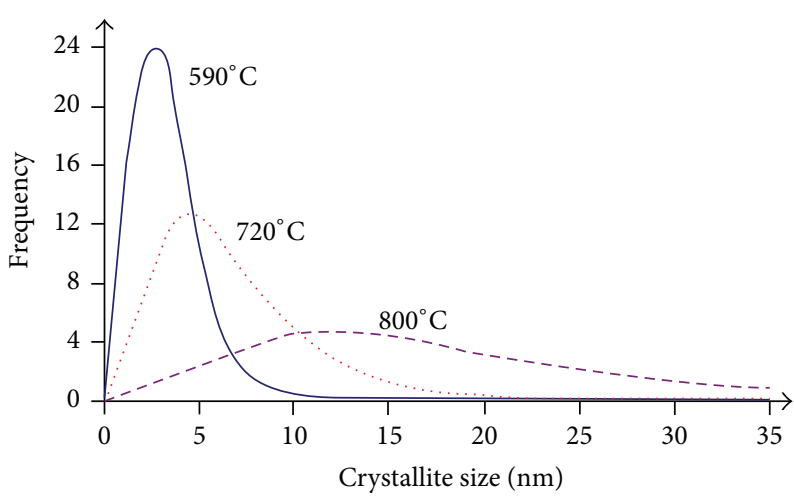

FIGURE 6: The distribution of the crystallite size of zirconium propionate ( $\mathbf{Z r}-\mathbf{1})$ calcined at different temperatures.

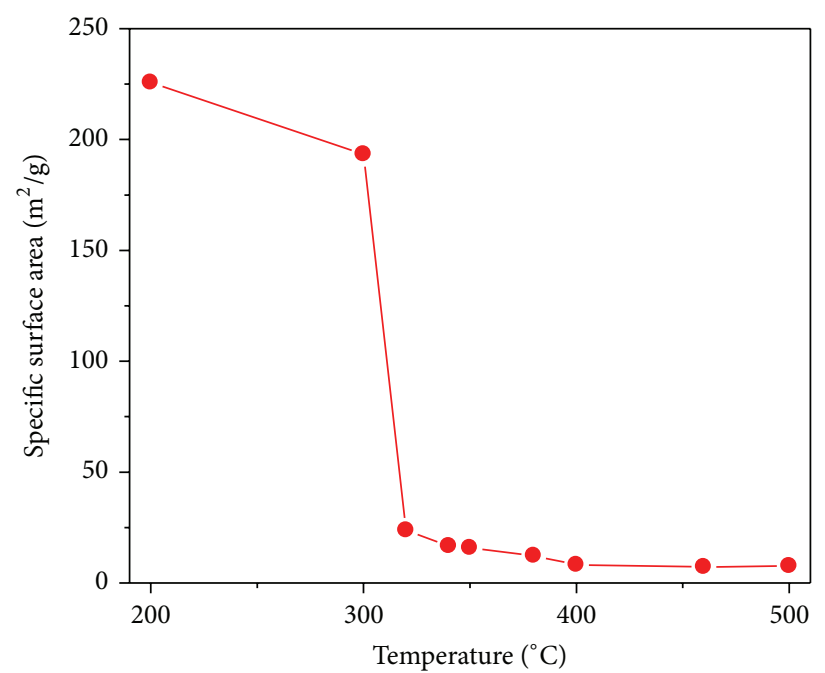

(a)

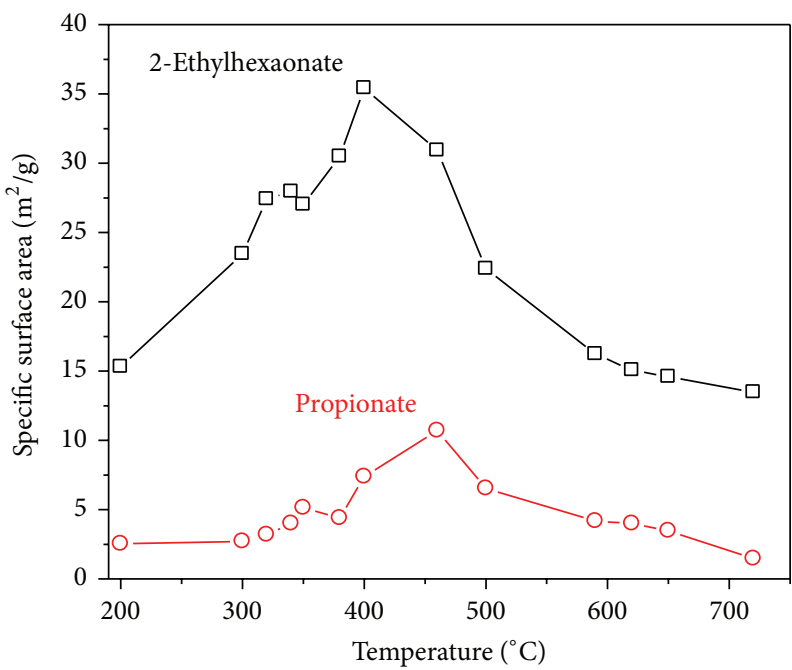

(b)

FIgURE 7: Specific surface area versus calcination temperature for zirconium carboxylate precursors. (a) Pivalate (Zr-5) and (b) propionate (Zr-2) and 2-ethylhexanoate (Zr-7).

tetragonal and cubic phases started to appear as a result of the transformation of the zirconium carboxylate to $\mathrm{ZrO}_{2}$. Upon heating to $590^{\circ} \mathrm{C}$, a more crystalline $\mathrm{t}-\mathrm{ZrO}_{2}$ phase was observed. Then, as the oxide was heated above $600^{\circ} \mathrm{C}$, a phase transformation occurred from the tetragonal phase to the monoclinic one. When the oxide was further calcined to $800^{\circ} \mathrm{C}$, the monoclinic phase was the dominant phase with about $90 \%$ relative abundance. In this study, a general trend was found for the phase transformation from the tetragonal to monoclinic phase with the initial crystallization of $\mathrm{ZrO}_{2}$ being detected between $350^{\circ} \mathrm{C}$ and $450^{\circ} \mathrm{C}$.

Figure 6 shows the $\mathrm{ZrO}_{2}$ crystallite size distribution calculated by application of Scherrer's equation [31] to the XRD patterns for zirconium propionate calcined at different temperatures. A slight increase in the average crystallite size from $3.2 \mathrm{~nm}$ to $6.7 \mathrm{~nm}$ was observed when the precursor was heated at $590^{\circ} \mathrm{C}$ and $720^{\circ} \mathrm{C}$, respectively. A bigger average crystallite size of $18.4 \mathrm{~nm}$ was observed when the sample calcined at $800^{\circ} \mathrm{C}$, in which the powder is almost completely transformed into the monoclinic phase (Table S3).
The phase transformation data and the surface area values are presented in Table S3. The results show that the zirconium oxides derived from aliphatic zirconium carboxylates undergo a phase transformation to the monoclinic system at higher temperature $\left(>720^{\circ} \mathrm{C}\right)$ than the $\alpha$-hydroxyl carboxylate complexes. The oxides derived from the thermal calcination of zirconium mandelate and zirconium hydroxybutyrate transformed into the monoclinic phase rapidly in the temperature range of $600^{\circ} \mathrm{C}$ to $720^{\circ} \mathrm{C}$. It can be concluded that the different coordination mode $\alpha$-hydroxy acids to zirconia leads to a different decomposition pathway that produces amorphous zirconium oxide with a structure predisposed to formation of monoclinic zirconia.

As depicted in Table S3 and Figure 7, the surface area results for the zirconium precursors showed a slight increase by the calcination due to the loss of the ligand and the formation of oxides with open pores. Further heating led to the gradual sintering of the oxide particles and decrease in the surface area. The precursors that showed a long order range and very high surface areas (zirconium pivalate) exhibited a 

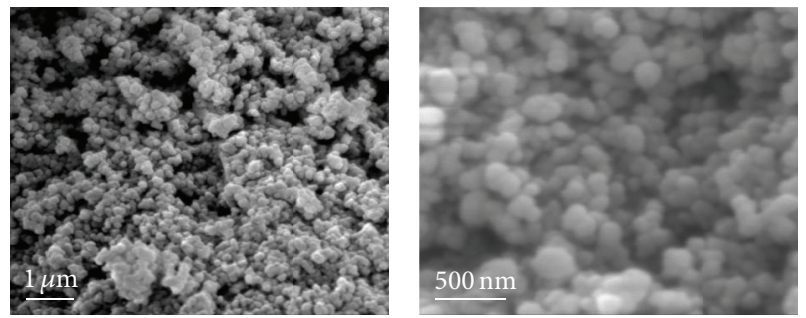

FIGURE 8: SEM images of the zirconia powders obtained from the thermal calcination of the zirconium carboxylate precursor of zirconium pivalate $(\mathbf{Z r}-\mathbf{5})$ calcined at $400^{\circ} \mathrm{C}$.

sharp decrease in the surface area due to the collapse of the metalloorganic framework upon formation of the oxide and then a slow decrease in the surface area due to the sintering process. Furthermore, $\mathrm{ZrO}_{2}$ obtained from the aliphatic carboxylates (Table S3) showed a dependence on the carboxylate ligands: the longer the carboxylate ligand chain, the higher the surface area of the resulting zirconia. For example, $\mathrm{ZrO}_{2}$ obtained from zirconium ethylhexanoate $(\mathrm{Zr}-7)$ showed a relatively higher surface area compared to that prepared from the other aliphatic zirconium carboxylate complexes. Also, to examine the influence of the zirconium carboxylate precursor on the morphology of the final oxide, scanning electron microscopy was performed. Figure 8 shows the SEM images of $\mathrm{ZrO}_{2}$ derived from the thermal treatment of the zirconium pivalate complex (Zr-5) at $400^{\circ} \mathrm{C}$, demonstrating the formation of agglomerates containing spherical nanosize particles with an approximate average diameter of about 100-200 nm.

\section{Conclusions}

Zirconia was prepared form of a variety of zirconium carboxylate complexes that were synthesized by the reaction of zirconium oxychloride with carboxylic acids or carboxylate salts in aqueous media. The carboxylates used in this study included aliphatic carboxylic acids and $\alpha$-hydroxyl carboxylic acids. It was determined that the aliphatic zirconium carboxylate complexes coordinate to the zirconium ions in a bridging bidentate mode, while a bridging chelating bonding with incorporation of the $\mathrm{OH}$ in the bonding was observed with the $\alpha$-hydroxyl carboxylate complexes. A vibrational-frequency calculation with a simplified structure of propanoic acid on $\mathrm{m}-\mathrm{ZrO}_{2}$ supports that a cis bidentate configuration is a more plausible structure. Notably, it was found that the nature of the zirconium carboxylate plays a profound role in the crystallinity, surface area, and other properties of the zirconia produced by their decomposition.

\section{Conflict of Interests}

The authors declare that there is no conflict of interests regarding the publication of this paper.

\section{Acknowledgments}

The authors acknowledge SABIC's management for the financial support of this research. DFT calculations were performed at KAUST Supercomputing Laboratory.

\section{References}

[1] M. Stoia, P. Barvinschi, L. Barbu-Tudoran, A. Negrea, and F. Barvinschi, "Influence of thermal treatment on the formation of zirconia nanostructured powder by thermal decomposition of different precursors," Journal of Crystal Growth, vol. 381, pp. 93-99, 2013.

[2] K. T. Jung and A. T. Bell, "Effects of catalyst phase structure on the elementary processes involved in the synthesis of dimethyl carbonate from methanol and carbon dioxide over zirconia," Topics in Catalysis, vol. 20, no. 1-4, pp. 97-105, 2002.

[3] N. V. Vlasenko, Y. N. Kochkin, and P. E. Strizhak, "Effect of acid-base characteristics of $\mathrm{ZrO}_{2}-\mathrm{Y}_{2} \mathrm{O}_{3}$ on catalytic properties in carboxylation of methanol," Theoretical and Experimental Chemistry, vol. 45, no. 4, pp. 271-275, 2009.

[4] W. H. Rhodes, "Controlled transient solid second-phase sintering of yttria," Journal of the American Ceramic Society, vol. 64, no. 1, pp. 13-19, 1981.

[5] F. F. Lange, “Transformation toughening," Journal of Materials Science, vol. 17, no. 1, pp. 240-246, 1982.

[6] R. N. Kapoor and R. C. Mehrotra, "Organic compounds of zirconium. V. Studies of zirconium mandelates," Journal of the American Chemical Society, vol. 80, no. 14, pp. 3569-3573, 1958.

[7] W. Blumenthal, The Chemical Behavior of Zirconium, Van Nostrand Company, Princeton, NJ, USA, 1958.

[8] R. C. Paul, O. B. Baidya, R. C. Kumar, and R. Kapoor, "Zirconium(IV) carboxylates," Australian Journal of Chemistry, vol. 29, no. 7, pp. 1605-1607, 1976.

[9] N. W. Alcock, V. M. Tracy, and T. C. Waddington, "Acetates and acetate-complexes. Part 1. Preparation of acetato-complexes and conductimetric studies in the acetic anhydride solvent system," Journal of the Chemical Society, Dalton Transactions, no. 21, pp. 2238-2242, 1976.

[10] M. L. Balmer, F. F. Lange, and C. G. Levi, "Metastable phase selection and partitioning in $\mathrm{ZrO}_{2}-\mathrm{MgO}$ processed from liquid precursors," Journal of the American Ceramic Society, vol. 75, no. 4, pp. 946-952, 1992.

[11] A. C. Geiculescu and H. G. Spencer, "Thermal decomposition and crystallization of aqueous sol-gel derived zirconium acetate gels: effects of the precursor solution $\mathrm{pH}$," Journal of Sol-Gel Science and Technology, vol. 16, no. 3, pp. 243-256, 1999.

[12] F. J. Berry, S. J. Skinner, I. M. Bell, R. J. H. Clark, and C. B. Ponton, "The influence of $\mathrm{pH}$ on zirconia formed from zirconium (IV) acetate solution: characterization by X-ray powder diffraction and Raman spectroscopy," Journal of Solid State Chemistry, vol. 145, no. 2, pp. 394-400, 1999.

[13] A. Samdi, B. Durand, M. Roubin et al., "Pressing and sintering behaviour of yttria stabilized zirconia powders prepared from acetate solutions," Journal of the European Ceramic Society, vol. 12, no. 5, pp. 353-360, 1993.

[14] L. N. Kommisarova, "New oxyacetates of zirconium and hafnium," Russian Journal of Inorganic Chemistry, vol. 8, no. 1, pp. 56-62, 1963.

[15] G.-Y. Guo and Y.-L. Chen, "Preparation and characterization of a novel zirconia precursor," Ceramics International, vol. 30, no. 3, pp. 469-475, 2004. 
[16] M. H. Al-Hazmi, Y. Choi, and A. W. Apblett, "Synthesis of zirconium oxide at low temperature using zirconium benzilate: an experimental and computational study," Science of Advanced Materials, vol. 6, no. 7, pp. 1438-1444, 2014.

[17] G. Svehla, Vogel's Quantitative Inorganic Analysis, Longman, London, UK, 7th edition, 1997.

[18] H. Toraya, M. Masahiro, and S. Somiya, "Calibration curve for quantitative analysis of the monoclinic-tetragonal $\mathrm{ZrO}_{2}$ system by X-ray diffraction," Journal of the American Ceramic Society, vol. 67, no. 6, pp. C119-C121, 1984.

[19] W. Kohn and L. J. Sham, "Self-consistent equations including exchange and correlation effects," Physical Review, vol. 140, no. 4, pp. A1133-A1138, 1965.

[20] G. Kresse and J. Hafner, "Ab initio molecular dynamics for liquid metals," Physical Review B, vol. 47, no. 1, pp. 558-561, 1993.

[21] G. Kresse and J. Furthmüller, "Efficient iterative schemes for ab initio total-energy calculations using a plane-wave basis set," Physical Review B: Condensed Matter and Materials Physics, vol. 54, no. 16, pp. 11169-11186, 1996.

[22] P. E. Blöchl, "Projector augmented-wave method," Physical Review B, vol. 50, no. 24, pp. 17953-17979, 1994.

[23] J. P. Perdew, K. Burke, and M. Ernzerhof, "Generalized gradient approximation made simple," Physical Review Letters, vol. 77, no. 18 , pp. 3865-3868, 1996.

[24] A. V. Ignatchenko, "Density functional theory study of carboxylic acids adsorption and enolization on monoclinic zirconia surfaces," The Journal of Physical Chemistry C, vol. 115, no. 32, pp. 16012-16018, 2011.

[25] H. J. Monkhorst and J. D. Pack, "Special points for Brillouinzone integrations," Physical Review B, vol. 13, no. 12, pp. 5188$5192,1976$.

[26] K. Nakamoto, Infrared and Raman Spectra of the Inorganic and Coordination Compounds, Wiley, New York, NY, USA, 5th edition, 1997.

[27] G. Deacon and R. Phillips, "Relationships between the carbonoxygen stretching frequencies of carboxylato complexes and the type of carboxylate coordination," Coordination Chemistry Reviews, vol. 33, no. 3, pp. 227-250, 1980.

[28] V. Bolis, G. Magnacca, G. Cerrato, and C. Morterra, "Effect of sulfation on the acid-base properties of tetragonal zirconia. A calorimetric and IR spectroscopic study," Topics in Catalysis, vol. 19, no. 3-4, pp. 259-269, 2002.

[29] C. Morterra, M. Peñarroya Mentruit, and G. Cerrato, "Acetonitrile adsorption as an IR spectroscopic probe for surface acidity/basicity of pure and modified zirconias," Physical Chemistry Chemical Physics, vol. 4, no. 4, pp. 676-687, 2002.

[30] V. Bolis, G. Magnacca, G. Cerrato, and C. Morterra, "Microcalorimetric and IR-spectroscopic study of the room temperature adsorption of $\mathrm{CO}_{2}$ on pure and sulphated $\mathrm{t}-\mathrm{ZrO}_{2}$," Thermochimica Acta, vol. 379, no. 1-2, pp. 147-161, 2001.

[31] A. W. Apblett, S. I. Kuriyavar, and B. P. Kiran, "Preparation of micron-sized spherical porous iron oxide particles," Journal of Materials Chemistry, vol. 13, no. 5, pp. 983-985, 2003. 

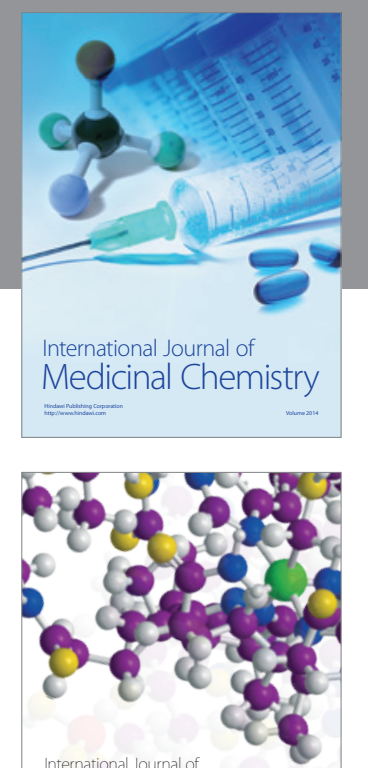

\section{Carbohydrate} Chemistry

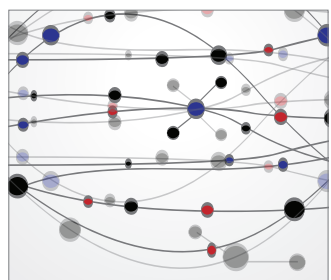

The Scientific World Journal
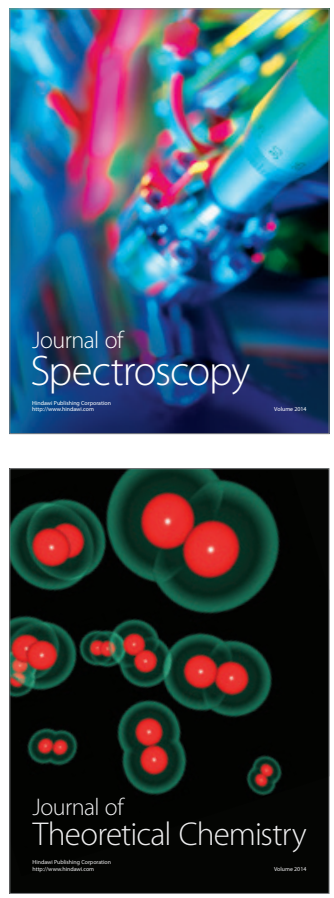
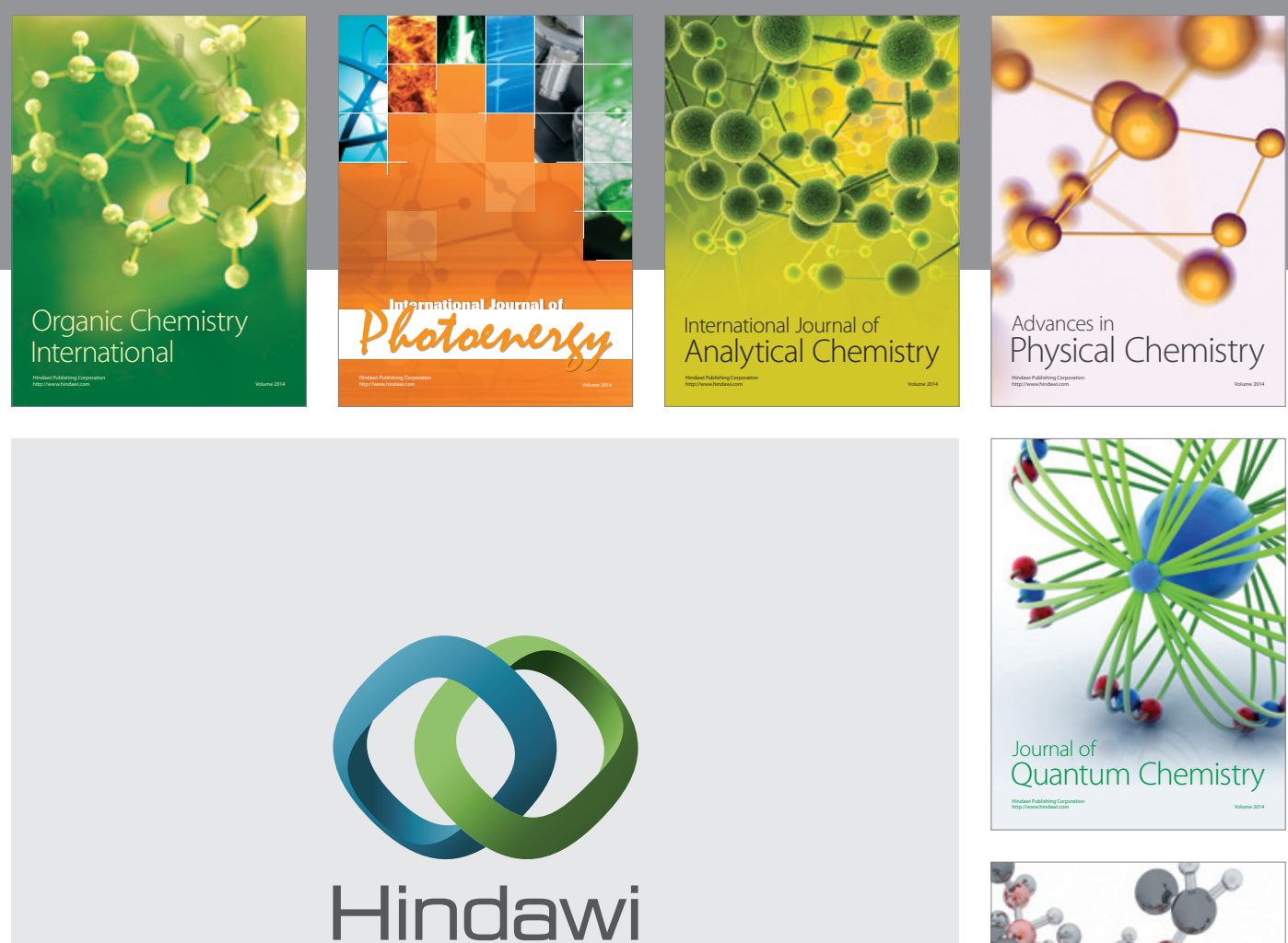

Submit your manuscripts at

http://www.hindawi.com

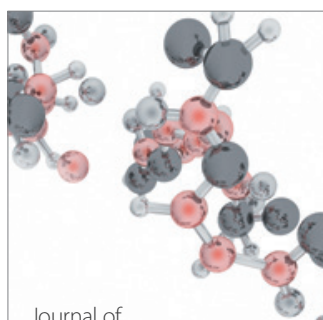

Analytical Methods

in Chemistry

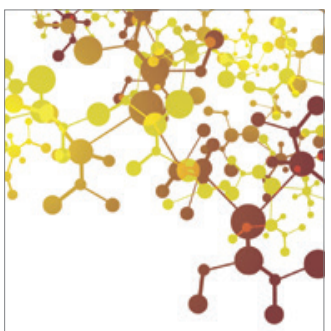

Journal of

Applied Chemistry

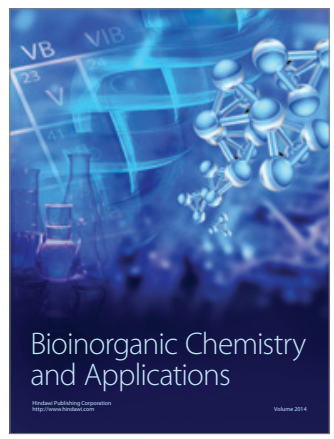

Inorganic Chemistry
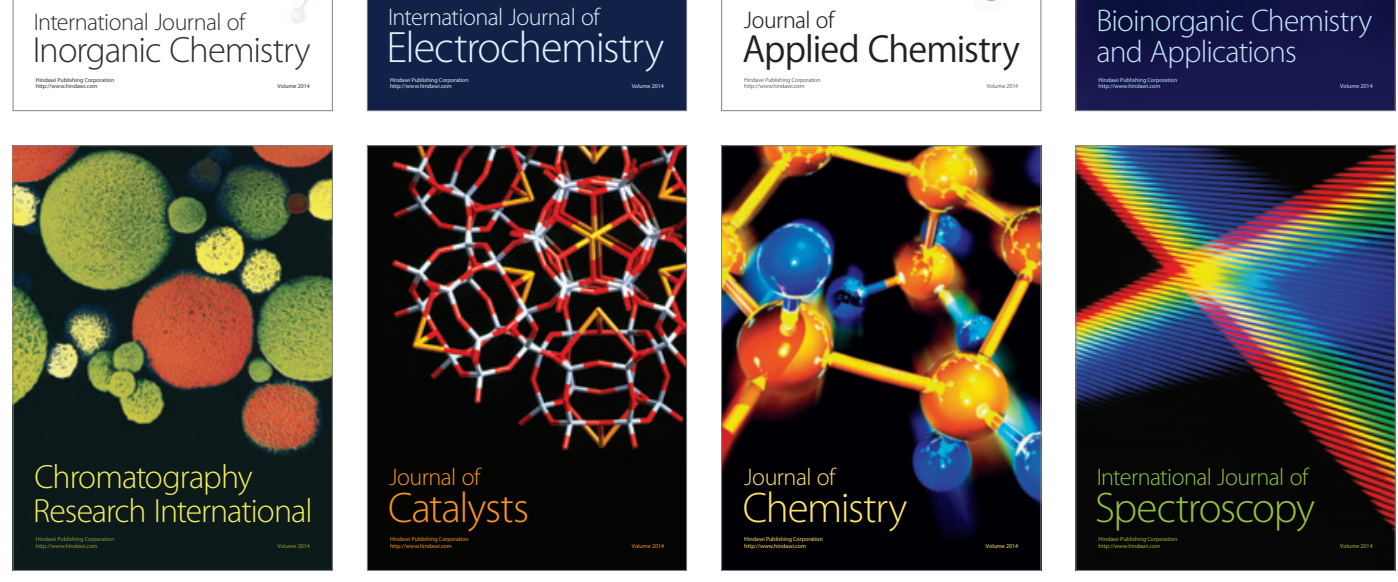